\title{
ELECTROTRANSFORMATION OF CULTURE CELLS
}

\section{E. Neumann und E. Boldt}

Faculty of Chemistry, Department of Physical and Biophysical Chemistry, University of Bielefeld, P.0. Box 8640, D-4800 Bielefeld 1, F.R.Germany

\section{Introduction}

Electric pulse methods become increasingly important for cell biology and biotechnology. Especially, the techniques of electroporation and electrofusion are of particular interest for cell transformation. Electrotransfection or electrotransformation, i.e. the direct transfer of DNA (or mRNA) into cells by electric impulses, appears to develop as the method of choice for the artificial gene transfer into chemically untreated cells, too.

Electric field pulse-mediated uptake of DNA into cells followed by the expression of the introduced gene was first demonstrated in $1982(1,2)$. The operative term 'electroporation' (electric pore formation) was introduced in order to specify the transient electropermeabilization of cell membranes as the physical basis of electrotransformation and of electrofusion. Applications of the electropermeabilization techniques include bacteria and yeast as well as plant and mammalian cells.

\section{Membrane Electropermeabilization}

Both electroporative gene transfer and electrofusion apparently are based on the same fundamental event: the reversible, non-destructive electropermeabilization of cell membranes by short-duration high electric field pulses, discovered in $1972(3,4)$. It was demonstrated that, above a threshold field strength, a controlled release of internal material from suspended membraneous vesicles (concomitant with uptake of solvent molecules) occurs in response to a field pulse in the 
microsecond range; there was no irreversible membrane damage (no dielectric breakdown). Apparently reversible changes in the membrane structure, of long-lived nature compared to the much shorter pulse duration, had been indicated by electro-optic techniques (5).

In contrast to reversible electroporation, irreversible and lethal effects on microorganisms caused by a whole series of similar electric field pulses had already been reported in $1967(6,7)$ : It was found that there is an inverse relationship between cell size and a critical external electric field strength $E_{c}$, necessary for, e.g., lysis of bacterial protoplasts ( 8 ). These results indicated that the cell membranes are the field-sensitive targets and, furtheron, that a critical transmembrane voltage $V_{c}$ (of about 1 Volt, independent of cell size) is built up by the external field pulses. Sale and Hamilton (8) suggested that the irreversible loss of the semipermeable membrane properties and ultimate lysis and cell death might be caused by conformational changes in the membrane structure.

In summary, short electric field pulses may either cause reversible or irreversible effects on membrane systems, depending on parameters such as the strength, duration, shape, and the number of the pulses. These early results remain fundamental also for the application of electric field pulses in the method of electroporative gene transfer. In the following we will focus on practical, experimental features important for electroporative gene transfer.

\section{Electroporative Gene Transfer}

Pulse Characteristics. High electric field pulses are conveniently applied to biological cells or other membrane particles by discharge of electric energy (current flow) through the suspension enclosed in a discharge chamber; this is readily achieved by the capacitor discharge (CD) technique adapted from fast relaxation kinetics (9). This technique was originally applied in the experiments on reversible electropermeabilization $(3,4)$. Obviously, because of its ease and fairly low-costs, the CD technique has been preferred in most of the recent papers on electroporative gene transfer. 
With respect to the time characteristics (shape) mainly two different types of electric field pulses are used for membrane electropermeabilization: either exponentially decaying pulses obtained by capacitor discharge, or rectangular (square) pulses delivered by, e.g., a cable discharge (10-12) or by special high voltage pulse equipment $(6,13)$. Because of maximum voltage and power requirements in the discharge circuit the technical realization of the equipment for given pulse shapes may vary considerably. These requirements are mainly defined by the geometry (electrode distance and surface, volume) of the discharge chamber, by the size and nature of the cells to be electroporated as well as by the electric conductance of the suspension.

The discharge of a storage capacitor of capacity $C$, charged to the desired initial voltage $V_{0}$ by a power supply, ensures a defined high electric field pulse. If the inductance of the discharge circuit is negligibly small, the time characteristics of the field pulse within the discharge chamber of electrode distance $d$ is given by $(9,3)$ :

$$
E(t)=E_{0} \exp (-t / \tau)
$$

with $E_{0}=V_{0} / d$ and $T=R \cdot C$.

The initial electric field strength $E_{0}$ as well as the time constant of the electrical discharge $\tau$ (i.e. the time of the field to decrease to $\left.E_{0} / e\right)$ are given to characterize the applied electric field pulse. The resistance $R$ of the discharge chamber filled with the cell suspension together with the chosen condensor capacity $C$ determines the pulse duration $(\tau)$.

Power supplies for electrophoresis, directly connected to a discharge chamber as described by Potter et al. (14), generally are not wellsuited for delivering defined exponential pulses. Strong discrepancies to the voltage knob settings usually occur (15) and direct measuring of the pulse characteristics (by oscilloscope) is necessary.

A broad variety of discharge chambers differing in geometry, volume, electrode material and other characteristics has been designed and used in practice for the application of nearly uniform (homogeneous) 
electric field pulses to cell suspensions. Closed and open chambers, mostly of cubic or cylindrical shape with the filling volume between parallel rectangular or disc electrodes, have been described $(3,6,13,16,17)$. The handling of fixed or variable volume is possible from several $\mathrm{ml}$ down to a few $\mu 1$. Concentric electrode arrangements providing a moderate inhomogeneous field distribution have also been chosen; commercially a special 'pipetting' discharge chamber based on this geometry has been designed. There are means for temperature control as well as for sterile and easy handling. Even a combination of controlled centrifugation with in situ electrical pulsing was reported. Among the most easy and popular designs are disposable plastic spectrophotometer cuvettes ('cuvette chamber', semimicro, $1 \mathrm{~cm}$ pathlength, 0.4 to $0.5 \mathrm{~cm}$ electrode distance, up to $1 \mathrm{ml}$ filling volume) with platinum or stainless steel paddle electrodes inserted (18) or aluminium foil electrodes directly glued to the cuvette walls (14). Most of the mentioned discharge chamber designs are meanwhile available as commercial equipments. In fact, commercial instruments for electroporation already emerged in 1984 (by W.Rauhaus, Fa. Dialog, Düsseldorf), and the number of manufacturers and models is still growing. For 'historical' reasons the first version of the original 'ELEKTROPORATOR $\mathbb{B}$ ', is reproduced in Fig. 1 .

Early data. After the finding of electric hemolysis of red blood cells (16) Auer et a1. (19) demonstrated the uptake of genetic material into human red blood cells permeabilized by an electric field pulse. Applying the capacitor discharge technique $\left(E_{0}=11 \mathrm{kV} / \mathrm{cm} ; \tau=100 \mu \mathrm{s}\right)$ Auer et al. succeeded in trapping ${ }^{3} \mathrm{H}$-labeled SV 40 DNA in the cells. Electric hemolysis as the first consequence of the pulsing was followed by a defined resealing procedure $\left(90 \mathrm{~min}\right.$ incubation at $\left.37^{\circ} \mathrm{C}\right)$ in the presence of the DNA or RNA. Up to $35 \%$ of the totally added linearized SV 40 DNA was finally detected within the cells. The entrapped DNA was DNAse resistant due to the package. The authors noticed that DNA trapping was much more effective with the linearized than with the supercoiled form of SV 40 DNA.

In 1982 electroporative gene transfer with subsequent actual gene expression was first reported $(1,2)$. Plasmid DNA carrying the 


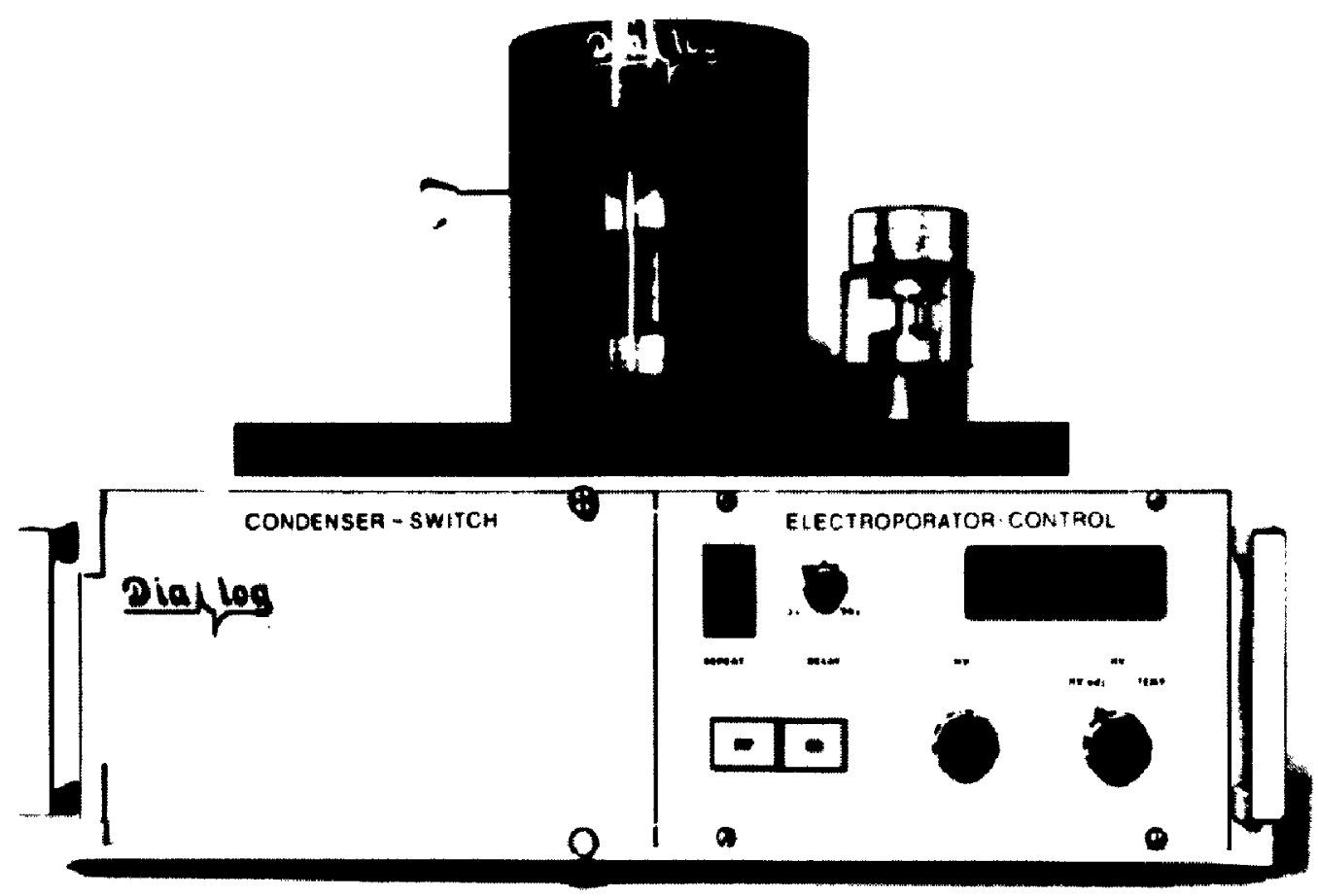

Fig. I The first commercial electroporation apparatus: El ektroporator $(\mathbb{B}$ of the Fa. Dialog, Düsseldorf, developed by W. Rauhaus.

thymidine kinase (tk) gene was introduced into tk deficient mammalian culture cells (mutant $\mathrm{L} \mathrm{tk}^{-}$mouse cells) by the application of short electric field pulses. Stable transformants surviving in the HAT selection medium proved the direct gene transfer and expression. Several main features of the procedure, already worked out in the early paper (2), became standard in current applications: (i) the highly conductive electroporation medium (HBS: HEPES buffered saline, with 140 $\mathrm{mM} \mathrm{NaCl}$ ); (ii) the fairly easy capacitor discharge (CO) technique for pulse application; (iii) the use of a few successive electric field pulses (e.g., three pulses at time intervals of several seconds); (iv) the necessity of a post-incubation of the cell-DNA mixture for about 10 min after pulsing, suggesting that the actual gene transfer is an 
after-field effect; ( $v$ ) the existence of a fairly sharp optimum in electric field strength, above a threshold value, for a given pulse duration in the microsecond range (e.g., $E_{0}=(8 \pm 0.5) \mathrm{kV} / \mathrm{cm}$ for $\tau=5$ $\mu s)$; ( $v i)$ the limitation of transfer efficiency at higher field strengths by lethal effects; (vii) the increase of the number of transfected colonies with an increase in cell density and plasmid DNA concentration; (viii) the linearization of the plasmid resulting in significantly higher transformation yield compared to the circular form.

In fact, the first direct gene transfer into plant protoplasts by electroporation was achieved in 1983 in our laboratory (by Shillito, Bierth and Neumann) along the lines of experience with animal cells. Lateron, a combination of electroporation with PEG (polyethylene glycol) treatment greatly enhanced the transformation efficiency (20). A similar combination of PEG treatment and electric field pulse application resulted in the transformation of bacterial protoplasts (21) and even of intact yeast cells (22).

The rapidly growing number of reports on electroporative gene transfer in the subsequent years, especially since 1985, demonstrates the general applicability of this technique not only for mamalian, but also for plant, bacterial and yeast cells. The experimental parameters of the procedure have been investigated in more detail, including (i) the temperature (pulsing and post-incubation at $0^{\circ} \mathrm{C}$ recommended); (ii) the pulse shape (exponential vs. rectangular); (iii) the pulse duration ( $\mu$ s vs. ms range); (iv) the addition of divalent ions to the electroporation medium $\left(\mathrm{Ca}^{2+}, \mathrm{Mg}^{2+}\right)$.

\section{Experimental Parameters}

Microsecond pulses. The reversibility of membrane electropermeabilization has been linked to a sufficiently short duration of the external electric field pulses applied. Using the experience accumulated until 1981, the first electroporative gene transfer experiments were performed with electric field pulse durations in the $\mu \mathrm{s}$-range in order to avoid irreversible destructive effects on 
the cell membranes. In fact, pulse times between 5 and 200 Hs for exponential and square pulses have been chosen in a number of systematic studies on 'electrotransfection' and 'electrotransformation' $(2,18,20,21,23-30)$. In some of the studies on electroporative gene transfer into plant protoplasts, equipment originally developed for cell electrofusion (square pulse generators and chambers) has been applied (28-30). The pulse times were also adapted from typical electrofusion conditions (1 to $100 \mu s)$, as well as the fairly high repetition rate in multipulse application. Because of power and field strength limitations, however, such equipment including dielectrophoresis set-up is not advised for systematic studies on electroporative gene transfer.

In the square pulse experiments with pulse times of 10 to $100 \mu \mathrm{s}$ it is necessary to set a sufficiently low conductance of the electroporation medium. This limitation was circumvented by Hama-Inaba et al. (27) using a 'semi-rectangular' pulse shape generated by a time-controlled cut-off of a fairly slow capacitor discharge. In this manner pulse times of up to 50 as can be realized even in high-conductance phosphate-buffered saline (PBS) medium.

A systematic comparison of exponential vs. rectangular pulse shapes with respect to electrotransfection efficiency is still lacking. In a paper dealing with this question (24) no clearcut conclusion could be drawn because, for technical reasons, different electroporation media for both types of experiments had to be used. Nevertheless, in these experiments with $\mathrm{k}^{-}$chinese hamster ovary (CHO) cells, exponential pulses resulted in a higher yield and revealed more specifically the threshold of the electric field strength that is typical for the electropermeabilization phenomenon.

Millisecond pulses. The alternative pulse duration range used in practice is between 5 and $20 \mathrm{~ms}$, initially obtained by chance (14); by directly discharging a standard electrophoresis power supply through a cuvette chamber using PBS as electroporation medium. Fromm et al. (15) showed that in this case, instead of the quoted $2000 \mathrm{~V}$ voltage setting, only some 120 to 150 Volts really are delivered to the cell suspension because of load mismatch within the discharge circuit. This creates an 
initial electric field strength of about $300 \mathrm{~V} / \mathrm{cm}$ and yields a nearly exponential pulse with $T=15$ to $20 \mathrm{~ms}$ (32). Nevertheless, electrotransfection was successful and because of the widespread availability of the equipment the experimental procedure described by Potter et a1. (14) was subsequently applied by many groups to a large variety of mammalian cell lines. Of course, no optimization with respect to electric field strength and pulse duration can be expected with only one 'standard' parameter setting. Recently, Chu et al. (33) reported on systematic reinvestigations of the electrotransfection of a variety of mammalian cell lines (ms-pulses by $C D$ ) and optimization with respect to various electroporation parameters.

Optimum electroporation conditions for transient expression and stable transformation of plant protoplasts were worked out by from et al. $(15,34)$ for ms-pulses delivered by $C D$. Fairly long electric field pulses were also applied to introduce TMV and CMV RNA and even whole TMV and CMV particles into tobacco protoplasts (35). The transformation of intact yeast cells with plasmid DNA was reported by Hashimoto et al. (22), who applied one or several ms-pulses in combination with PEG treatment and long incubation times. Thus, millisecond pulse durations have turned out to be also useful in electroporative gene transfer. These conditions became popular especially due to the reduced electric field strength necessary in combination with these longer pulse times. Charging voltages of only 200 to $400 \mathrm{~V}$ turn out to be sufficient (standard $0.4 \mathrm{~cm}$ electrode distance in cuvette chambers, pulse times between 2 and $20 \mathrm{~ms})$ as reported for mammalian cells $(32,33)$ and for plant protoplasts $(15,34,35)$.

A systematic comparison of $\mu s-$ vs. ms-pulses with respect to transfection efficiency using the same transfection system has been tried by Shigekawa (32). CHO cells where transfected with the pSVneo vector; pulses of $500 \mu \mathrm{s}$ and pulses of 2 to $10 \mathrm{~ms}$ were compared. As already mentioned in the comparison between exponential and square pulse shapes, because of technical limitations no clearcut result was obtained. For the ms-pulses a fairly narrow peak was observed in the voltage dependence of transfection efficiency $(1 \mathrm{kV} / \mathrm{cm}$, at about 60 to $80 \%$ cell survival). At higher fields the survival rate very quickly decreased, thus limiting the useful range of field strength. In 
contrast, a much broader dependence is seen for the shorter pulses (500 $\mu \mathrm{s})$, but in this case the maximum transfection efficiency unfortunately could not be reached because of voltage limitation of the equipment.

Electric Field Strength. One of the fundamental characteristics of membrane electropermeabilization by short electric field pulses in the us-range is the existence of a threshold electric field strength for the onset of reversible permeability changes (3). A corresponding critical transmembrane voltage of $V_{c} \approx 0.5$ to $1 V$ has been established in many cases. For practical purposes, the necessary critical external electric field strength $E_{c}$ can be estimated $(4,8)$ :

$$
E_{C}=\frac{4 V_{C}}{3 D}
$$

13.3 to 6.7

$$
E_{c} / \mathrm{kV} \mathrm{cm}^{-1} \approx \frac{13.3 / \mu \mathrm{m}}{0 / 06.7}
$$

where $D$ is the diameter of the suspended spherical cells. Such estimates are, however, only crude approximations. A variety of parameters such as, for instance, the cell membrane composition and the physiological state of the cells, will affect the value of $E_{c}$. of course, the inverse relationship between $E_{C}$ and the dimensions of the cells is fundamental: electroporation of small bacteria requires much higher field strengths than that of big plant protoplasts (at the same pulse duration).

In this connection the relationship between pulse duration and critical electric field strength is practically important, but there is no quantitative general expression for the functional dependence between these parameters. Therefore, it became common practice to study the survival of cells after treatment with electric pulses of increasing field strength, as proposed in the original electric gene transfer experiments $(1,2)$. The resulting 'survival curves' for given conditions (pulse duration and shape, medium, temperature) are the basis for 
selecting electroporation conditions for the actual gene transfer experiments. A typical example of a survival curve and of the field strength dependence of electrotransformation is shown in Fig.2. It has to be noted that there are noticeable differences between short-term survival (judged, e.g., within $2 \mathrm{~h}$ after pulsing by dye exclusion test) and long-term growth ability of electrically treated cells $(26,27)$. Long-term stability is needed for successful electrotransfection.

Numerous reports have established that a relative optimum in electrotransfection efficiency exists at field strengths yielding survival rates between 80 and $30 \%(1,2,15,22,23,26,27,33)$. These results can be qualitatively rationalized in the following way. If the field strength of the electric pulses is increased, reversible electroporation precedes the irreversible membrane permeability changes (break-down) leading to cell death. Successful electroporative gene transfer only occurs in the range of reversible electric field effects (reversible electroporation). Cell populations are usually nonsynchronized and often have a fairly broad size distribution. A field pulse of given strength is only critical for the subpopulation of cells of proper size; this portion will become electrotransfected successfully. The lethal effects indicate the upper limit of the reversibility range of the electric field pulse effects.

Electric field strength limitations were critical in some experiments to electrotransform small objects 1 ike bacteria or yeast $(21,23,32)$; the optimum field strength for maximum transformation efficiency was not revealed, partly because of technical reasons. We also may mention early attempts on electrotransformation of Bac. subtilis (Berg and Grunow, 1979, unpublished; Neumann and SüBmuth, 1982, unpublished) which were not successful with short $\mu \mathrm{s}$-pulses in the field strength range available (up to about 30 to $40 \mathrm{kV} / \mathrm{cm}$ ).

One recent example from our laboratory may illustrate the typical approach to elaborate suitable electroporation conditions. In attempts to electrotransform gram-positive amino acid producing Corynebacteria (Wolf, Pühler and Neumann, 1987, unpublished). At first, the survival of osmotically sensitized cells (spheroplasts) has been investigated at the pulse durations of $5 \mu \mathrm{s}, 300 \mu \mathrm{s}$, and $5 \mathrm{~ms}$; different media as well as different equipments had to be used. It was noticed that pulses of 


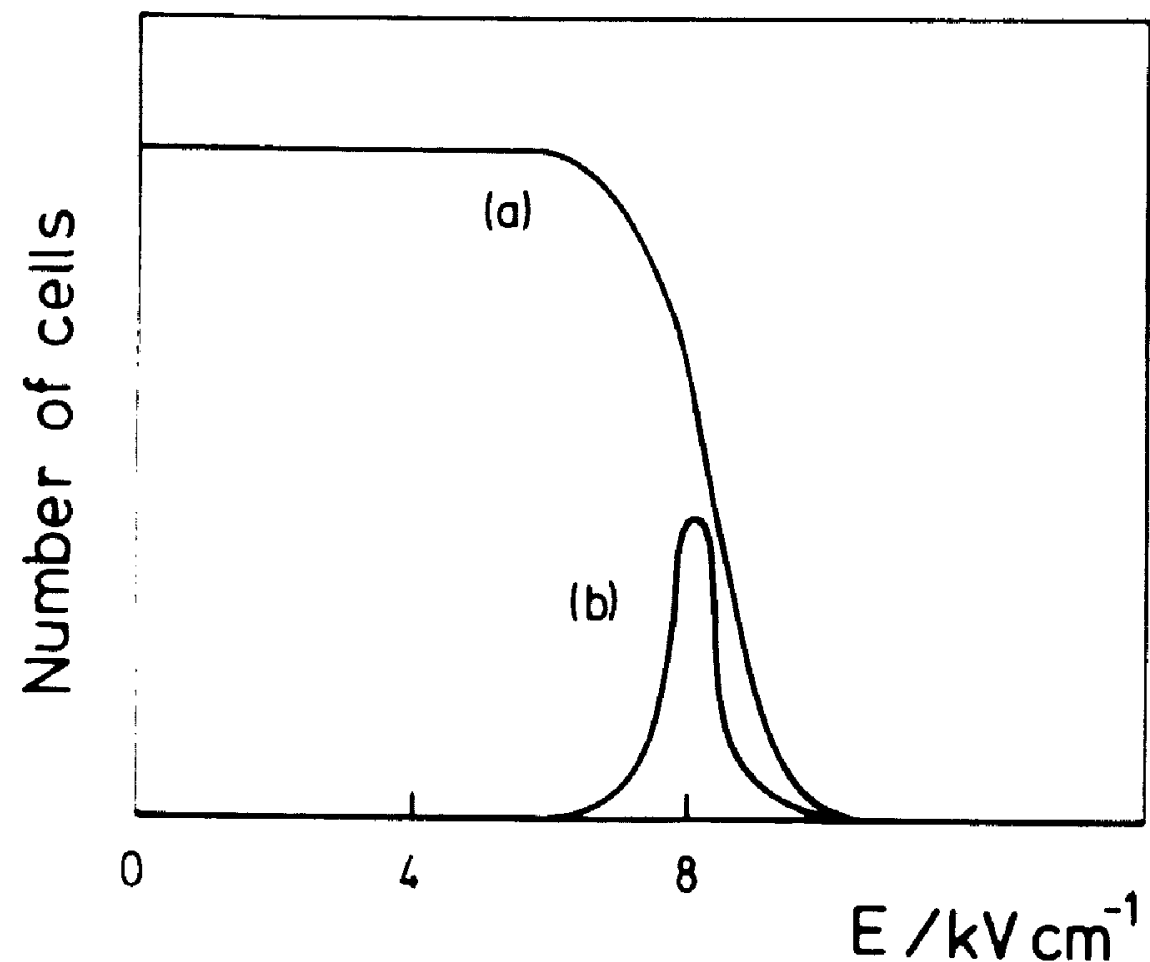

Electric field strength

Fig. 2 Scheme (a) of survival curve and (b) of the number of electrotransformed cells.

even up to $E_{0}=40 \mathrm{kV} / \mathrm{cm}$ with the $5 \mu \mathrm{s}$-pulses did not affect the viability of the bacterial spheroplasts. In contrast, with the longer pulse durations lethal effects were observed within the field strength ranges available (up to $25 \mathrm{kV} / \mathrm{cm}$ for the $300 \mu \mathrm{s}$-pulses and up to 6 $\mathrm{kV} / \mathrm{cm}$ for the $5 \mathrm{~ms}$-pulses). At field strengths of $20 \mathrm{kV} / \mathrm{cm}$ and $300 \mu \mathrm{s}$ pulses $60 \%$ survival and stable transformants were obtained after regeneration and selection.

Electroporation Medium. Already in the very first electrotransfections of mammalian cell lines highly conductive media were used: HEPES buffered saline (HBS) (2) or PBS $(1,14)$; they are now standard media (without divalent ions added). The cells are usually washed and 
resuspended just before electropermeabilization in one of these media. After mixing with the plasmid DNA the suspension is pulsed ('zapped') and, after an incubation period (see below), transferred to the growth medium.

The influence of divalent cations $\left(\mathrm{Mg}^{2+}, \mathrm{Ca}^{2+}\right)$ on the transfection efficiency was investigated $(1,2,15,30)$. While $\mathrm{Mg}^{2+}$ ions increase the DNA adsorption on the cell surfaces, the actual overall electrotransfection efficiency is largest without addition of these ions $(1,2)$. Therefore, divalent ions usually are not added to mammalian cells.

In the case of plant protoplasts, it has been found that, besides the necessary osmotic stabilization by sugars such as mannitol most oftenly $4 \mathrm{mM} \mathrm{CaCl} 2$ is favourable (15). Hibi et al. (30) attempted to study systematically the effect of $\mathrm{Mg}^{2+}$ and $\mathrm{Ca}^{2+}$ ions on the electrotransfection of tobacco protoplasts by TMV RNA. Because of technical limitation they could only check the concentration range up to $100 \mu \mathrm{M}$; there was no effect of $\mathrm{Ca}^{2+}$ ions, confirming Nishiguchi et a1. (31) who found that there is no dependence on $\mathrm{Ca}^{2+}$ ions up to $8 \mathrm{mM}$. on the other hand, $\mathrm{Mg}^{2+}$ ions at $100 \mu \mathrm{M}$ had a small promotive effect. The optimized electrotransformation protocol by Shillito et al. (20) for tobacco leaf protoplasts applies $6 \mathrm{mM} \mathrm{MgCl} 2 \cdot \mathrm{Mg}^{2+}$ ions have been reported to be essential for electric field mediated transformation of carrot protoplasts (28). In summary, with plant protoplasts usually some divalent ions up to about $5 \mathrm{mM}$ are added to the electroporation medium.

The nature of the buffer used (e.g., PBS, HBS, or MES) has no marked influence on tobacco protoplasts if TMV RNA is electrically introduced. The yield is also independent of the $\mathrm{pH}$ value between $\mathrm{pH} 5$ to 8 (35). Fromm et al. (15) found a dependence of the efficiency of transient expression (CAT activity) in electrotransformed carrot protoplasts on PBS concentration. However, this dependence most probably reflects the different pulse times. Therefore the different survival rates result from the increased electric resistance by dilution of the PBS buffer; see eq. (1). Chu et al. (33) studied the dependence of the CAT activity of mammalian cells after electroporative gene transfer on salt concentration in a HEPES buffer. The salt concentration was varied 
between 25 and $100 \mathrm{mM} \mathrm{NaCl}$ keeping the osmolarity constant by the addition of sucrose. The highest salt concentration (100 mM) gave the strongest CAT signal, and standard HBS buffer with $137 \mathrm{mM} \mathrm{NaCl}$ was even more suitable. It is fair to say that at present the role of different pulse time constants due to changing salt concentrations remains unclear.

Besides of proper choice of the electroporation medium for pulsing, special medium conditions may also be favorable for the membrane resealing process after pulsing, as has been claimed by Stopper et al. (25); this study beautifully confirms the early electroporation data of mouse L cells by Wong and Neumann (1) and Neumann et al. (2).

Incubation Times and Temperature. It was already noticed in the very first electroporative gene transfer experiments (2) that a postincubation period for the cell-DNA mixture of up to $10 \mathrm{~min}$ after the electric field pulse application is necessary for effective gene transfer resulting in gene expression. This clearly indicates that the ONA uptake is an after-field effect which is triggered by the shortduration electric field pulse.

The longevity of the reversibly electropermeabilized membrane state is well-known (2) and has been studied systematically by following the uptake of normally impermeable molecules (drugs, dyes), added to the cells at different times after pulse application; see, e.g., $(36,37)$. A strong temperature dependence of the resealing process has been found. It has been repeatedly reported that at low temperature the electropermeabilized state of the cell membranes can be maintained for minutes and even up to an hour (38). The slow resealing at low temperature fits well the observation made in electrotransfection experiments (14); the efficiency of gene expression can be increased by pulsing and post-incubation at low temperature. Thus, electroporative gene transfer experiments are usually performed at $0^{\circ}$ to $4^{\circ} \mathrm{C}$. According to a standard protocol oftenly used, the washed cells are resuspended in 'ice-cold' electroporation buffer and the plasmid DNA is added. Then this mixture is incubated for 5 to 10 min and one or several pulses are applied. After a post-incubation of about $10 \mathrm{~min}$ (all at the low 
temperature) the cells are transferred to growth medium at the necessary elevated temperature.

This protocol also reflects some of the supposed steps in the overall electrotransfection and electrotransformation procedures: (i) The necessary DNA/cell contact is established within the pre-incubation period by DNA adsorption on the cell membrane surface. Adsorption may be enhanced either by charge neutralization through the binding of divalent cations or by pretreatment with enzymes partially removing the extracellular matrix or cell walls. (ii) DNA transport across the cell membrane is initiated by one or several subsequent short electric field pulses. (iii) The actual permeation is a sequence of fairly slow (msto min-range) but still unknown 'transfer-steps' within the postincubation period. (iv) The DNA transport is terminated by membrane resealing at elevated temperature. (v) If the DNA is inside the cell, obviously intracellular events lead to actual gene expression.

Number of Electric Field Pulses. The possible advantage of the application of several subsequent field pulses (e.g., 3 to 5 pulses at time intervals of several seconds) is not yet clear. Two simple effects might be envisaged in this respect. First, a mere summation of the favorable events might occur if, after the second pulse, other independent sites of DNA/Cell contacts become electroporated and thus involved in DNA-transfer steps. Second, if the.time between two pulses is small compared to the rotational diffusion time of the cells, a second pulse could enhance or accelerate, at the same electropermeabilized patch, the sequence of transfer steps following an event triggered by the first pulse. Most probably this has been the case in the study by Hama-Inaba et al. (27), where the time interval between two pulses was only $50 \mathrm{~ms}$. Here, the efficiency in the doublepulse experiment was higher than that in an optimized single-pulse experiment.

Linearization of plasmid DNA. If tolerable, plasmid DNA should be linearized for electroporative gene transfer experiments. An enhancement of the gene expression yield between 3-and 20-fold with linearized plasmid DNA compared to the circular or supercoiled form 
has been observed by several authors for different kinds of cells, for transient expression as well as for stable transformation $(2,14,20,25,39,40)$. These observations point to a possible mechanism of electroporative DNA transfer and might be correlated with the size of the electropores or 'electrocracks' (41) necessary for transfer steps. It is expected that the permeation sites for the linear DNA molecules (fitting the diameter of a hydrated double-helical DNA 'rod') can be smaller than those necessary for a supercoiled, i.e., more 'globular', tertiary structure.

Addition of Carrier DNA. It is well-known from classical transfection, transformation, and microinjection procedures that the addition of 'carrier' DNA, i.e., of non-specific high-molecular DNA, leads to an increase in the level of gene expression of the specific plasmid transferred (42). A similar positive effect of the addition of carrier DNA to the cell-plasmid DNA mixture was also established in electrotransfection experiments $(20,28,33)$. The nature of the carrier DNA was found to be important (33), in line with the data of other, non-electroporative cell transfection and transformation methods.

The mechanism of the effect of carrier DNA is still unknown. It is argued that it is linked to the activity of intracellular nucleases. In the presence of excess carrier DNA a sufficient amount of the specific foreign plasmid DNA obviously is preserved from cleavage.

\section{Conclusions}

Recent progress in molecular genetics and in biotechnology demostrates that efficient and reliable gene transfer is an important prerequisite. It appears that direct transfer of DNA or MRNA by electroporation is not only simple and readily controlled but also generally applicable. The efficiency of the electric technique in many cases compares well with, and in several cases of special interest is clearly superior to, the chemical methods.

One of the main aims of further improvements of DNA transfer techniques is the development of conditions such that cells can be transformed 
without excessive pretreatment, avoiding, e.g., protoplast formation. Electroporative gene transfer, to our opinion, is a likely candidate to realize these goals. In addition, easy and reliable handling of the electroporation method together with further technical development of equipment will make this method even more attractive to a broad range of cell biologists and biotechnologists.

\section{Acknowledgements}

We gratefully acknowledge financial support by the OFG (grant NE 227/4 to E.N.).

\section{References}

1. Wong, T.-K., Neumann, E., 1982. Electric field mediated gene transfer. Biochem. Biophys. Res. Commun. 107, 584-587.

2. Neumann, E., Schäfer-Ridder, M., Wang, Y., Hofschneider, P.H., 1982. Gene transfer into mouse lyoma cells by electroporation in high electric fields. EMBO J. 1, 841-845.

3. Neumann, E., Rosenheck, K., 1972. Permeability changes induced by electric impulses in vesicular membranes. J. Membr. Biol. 10, 279290.

4. Neumann, E., Rosenheck, K., 1973. Potential differences across vesicular membranes. J. Membr. Biol. 14, 194-196.

5. Rosenheck, K., Lindner, P., Pecht, 1., 1975. Effect of electric fields on light scattering and fluorescence of chromaffin granules. J. Membr. Biol. 20, 1-12.

6. Sale, A.J.H., Hamilton, W.A., 1967. Effects of high electric fields on microorganisms. I. Killing of bacteria and yeasts. Biochim. Biophys. Acta 148, 781-788.

7. Hamilton, W.A., Sale, A.J.H., 1967. Effects of high electric fields on microorganisms. II. Mechanism of action of the lethal effect. Biochim. Biophys. Acta 148, 789-800.

8. Sale, A.J.H., Hamilton, W.A., 1968. Effects of high electric fields on microorganisms. III. Lysis of erythrocytes and protoplasts. Biochim. Biophys. Acta 163, 37-43.

9. Eigen, M., DeMaeyer, L., 1963. Relaxation Methods. In: Techniques of Organic Chemistry, Volume 8(2) (S.L. Friess, E.S. Lewis, A. Weissberger, eds.). John Wiley, New York, pp. 895-1054.

10. Ilgenfritz, G., 1966. Chemische Relaxation in starken elektrischen Feldern, Dissertation, Universität Göttingen. 
11. Grünhagen, H.H., 1973. Fast Spectrophotometric Detection System for Coupled Physical and Chemical Electric Field Effects in Solution. Biophysik 10, 347-354.

12. Lindner, P., Neumann, E., Rosenheck, K., 1977. Kinetics of permeability changes induced by electric impulses in chromaffin granules. J. Membr. Biol. 32, 231-254.

13. Kinosita, K., Jr., Tsong, T.Y., 1977. Hemolysis of human erythrocytes by a transient electric field. Proc. Natl. Acad. Sci. 74, 1923-1927,

14. Potter, H., Weir, L., Leder, P., 1984. Enhancer-dependent expression of human $x$ immunoglobulin genes introduced into mouse pre-B lymphocytes by electroporation. Proc. Natl. Acad. Sci. 81, $7161-7165$.

15. Fromm, M., Taylor, L.P., Walbot, V., 1985. Expression of genes transferred into monocot and dicot plant cells by electroporation. Proc. Natl. Acad. Sci. 82, 5824-5828.

16. Zimmermann, U., Pilwat, G., Riemann, F., 1974. Dielectric breakdown of cell membranes. Biophys. J. 14, 881-899.

17. Berg, H., Augsten, K., Bauer, E., Förster, W., Jacob, H.-E., Mühlig, P., Weber, H., Kurischko, A., 1984. Possibilities of celi fusion and transformation by electrostimulation. Bioelectrochem. Bioenerg. 12, 119-133.

18. Evans, G.A., Ingrahan, H.A., Lewis, K., Cunningham, K., Seki, T., Moriuchi, T., Chang, H.C., Silver, J., Hyman, R., 1984. Expression of the Thy-1 glycoprotein gene by DNA-mediated gene transfer. Proc. Nat1. Acad. Sci. 81, 5532-5536.

19. Auer, D., Brandner, G., Bodemer, W., 1976. Dielectric breakdown of the red blood cell membrane and uptake of SV 40 DNA and mammallian cell RNA. Naturwiss. 63, 391-391.

20. Shillito, R.D., Saul, M.W., Paszkowski, J., Müller, M., Potrykus, I., 1985. High efficiency direct gene transfer to plants. Bio/Technology $\underline{3}, 1099-1103$.

21. Shivarova, N., Förster, W., Jacob, H.-E., Grigorova, R., 1983. Microbiological implications of electric field effects. VII. Stimulation of plasmid transformation of Bacillus cereus protoplasts by electric field pulses. Z. Allg. Mikrobiol. 23, 595599.

22. Hashimoto, H., Morikawa, H., Yamada, Y., Kimura, A., 1985. A novel method for transformation of intact yeast cells by electroinjection of plasmid DNA. Appl. Microbiol. Biotechnol. 21, 336-339.

23. Karube, I., Tamiya, E., Matsuoka, H., 1985. Transformation of Saccharomyces cerevisiae spheroplasts by high electric pulse, FEBS Lett. 182, 90-94.

24. Zerbib, D., Amalric, F., Teissie, J., 1985. Electric field-mediated transformation: Isolation and characterization of a $\mathrm{TK}^{+}$subclone. Biochem. Biophys. Res. Commun. 129, 611-618.

25. Stopper, H., Zimmermann, U., Wecker, E., 1985. High yield of DNAtransfer into mouse L-cells by electropermeabilizition. Biosciences 40, 929-932.

26. Riggs, C.D., Bates, G.W., 1986. Stable transformation of tobacco by electroporation: Evidence for plasmid concatenation. Proc. Natl. Acad. Sci. 83, 5602-5606. 
27. Hama-Inaba, H., Shiomi, T., Sato, K., Ito, A., Kasai, M., 1986. Electric pulse-mediated gene transfer in mammalian cells grown in suspension culture. Cell Structur and Function 11, 191-198.

28. Langridge, W.H.R., Li, B.J., Szalay, A.A., 1985. Electric field mediated stable transformation of carrot protoplasts with naked DNA. Plant Cel1 Reports 4, 355-359.

29. Ou-Lee, T.-M., Turgeon, R., Wu, R., 1986. Expression of a foreign gene linked to either a plant-virus or a Drosophila promoter after electroporation of protoplasts of rice, wheat, and sorghum. Proc. Natl. Acad. Sci. 83, 6815-6819.

30. Hibi, T., Kano, H., Sugiura, M., Kazami, T., Kinura, S., 1986. High efficiency electro-transfection of tobacco mesophyll protoplasts with TMV RNA. J. General Virology 67, 2037-2042.

31. Nishiguchi, M., Langridge, W.H.R., Szalay, A.A., Zaitlin, M., 1986. Electroporation-mediated infection of tobacco leaf protoplasts with tobacco mosaic virus RNA and cucumber mosaic virus RNA. Plant Cell Reports $\underline{5}, 57-60$.

32. Shigekawa, K., 1987. Gene-Transfer in Prokaryotic and Eukaryotic Cells by Electroporation. In: Bio-Rad Labs, chapter 2, pp. 1-14.

33. Chu, G., Hayakawa, H., Berg, P., 1987. Electroporation for the efficient transfection of mamalian cells with DNA. Nucl. Acid. Res. 15, 1311-1326.

34. Fromm, M.E., Taylor, L.P., Walbot, V., 1986. Stable transformation of maize after gene transfer by electroporation. Nature 319,791 793.

35. Okada, K., Nagata, T., Takebe, I., 1986. Introduction of functional RNA into plant protoplasts by electroporation. Plant Cell Physiol. 27, 619-626.

36. Jacob, H.-E., Förster, W., Berg, H., 1981. Microbiological implications of electric field effects. II. Inactivation of yeast cells and repair of their cell envelope. Z. Allg. Mikrobiol. 21, 225-233.

37. Teissie, J., Rols, M.P., 1986. Fusion of mammalian cells in culture is obtained by creating the contact between cells after their electropermeabilization. Biochem. Biophys. Res. Commun. 140, 258266.

38. Knight, D.E., Baker, P.F., 1982. Calcium-dependence of catecholamine release from bovine adrenal medullary cells after exposure to intense electric fields. J. Membrane Biol. 68, 107-140.

39. Falkner, F.G., Neumann, E., Zachau, H.G., 1984. Tissue specificity of the initiation of immunoglobul in $\alpha$ gene transcription. HoppeSeyler's Z. Physiol. Chem. 365, 1331-1343.

40. Toneguzzo, F., Hayday, A.C., Keating, A., 1986. Electric fieldmediated DNA transfer: Transient and stable gene expression in human and mouse lymphoid cells. Mol. Cell. Biol. 6, 703-706.

41. Sugar, I.P., Förster, W., Neumann, E., 1987. Model of cell electrofusion. Membrane elecroporation, pore coalescence and percolation. Biophysical Chemistry 26, 321-335.

42. Krens, F.A., Molendijk, L., Wullems, G.J., Schilperoort, R.A., 1982. In vitro transformation of plant protoplasts with Ti-plasmid DNA. Nature 296, 72-74. 